\title{
Influence of the substrate gas-inlet gap on the growth rate, morphology and microstructure of zirconium carbide films grown by chemical vapour deposition
}

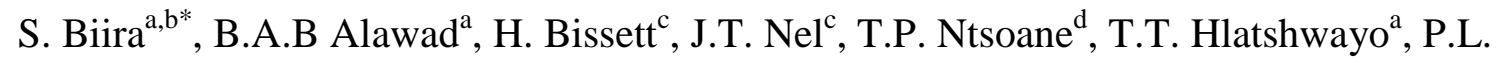 \\ Crouse $^{\mathrm{e}}$, J.B. Malherbe ${ }^{\mathrm{a}}$ \\ ${ }^{a}$ Department of Physics, University of Pretoria, Pretoria, 0002 South Africa \\ ${ }^{b}$ Department of Physics, Busitema University, P.O. Box 236, Tororo, Uganda \\ ${ }^{c}$ Applied Chemistry Division, The South African Nuclear Energy Corporation (Necsa), P.O. Box 582, Pretoria, \\ 0001 South Africa \\ ${ }^{d}$ Radiation Science Division, The South African Nuclear Energy Corporation (Necsa), P.O. Box 582, Pretoria, \\ 0001 South Africa \\ ${ }^{e}$ Department of Chemical Engineering, University of Pretoria, 0002 South Africa \\ *Corresponding Author: Tel.: +27611 894 594, E-mail address: bsaphina@yahoo.co.uk
}

\begin{abstract}
The influence of the gap between the gas inlet and the substrate in an in-house developed thermal chemical vapour deposition (CVD) reactor, on the growth rate, surface morphology, phase composition and microstructure of deposited $\mathrm{ZrC}$ films was investigated by $\mathrm{X}$-ray diffraction (XRD) and scanning electron microscopy (SEM). The $\mathrm{ZrC}$ films were grown on high density graphite substrates at different substrate-inlet gaps, viz. $70 \mathrm{~mm}, 90 \mathrm{~mm}, 120 \mathrm{~mm}$, $145 \mathrm{~mm}$ and $170 \mathrm{~mm}$, at substrate temperatures of $1200{ }^{\circ} \mathrm{C}$ and $1400{ }^{\circ} \mathrm{C}$. The growth rate of ZrC films prepared at $1400{ }^{\circ} \mathrm{C}$ was observed to be higher than at $1200{ }^{\circ} \mathrm{C}$., and was found to
\end{abstract}


decrease with increase in substrate-inlet gap at both temperatures. The boundary layer thickness increased with an increase in substrate-inlet gap. The diffusion coefficients of the reactants were found to be $0.176 \mathrm{~cm}^{2} / \mathrm{s}$ and $0.200 \mathrm{~cm}^{2} / \mathrm{s}$ for the $\mathrm{ZrC}$ films deposited at 1200 ${ }^{\circ} \mathrm{C}$ and $1400{ }^{\circ} \mathrm{C}$ respectively. A model illustrating the diffusion of source materials through the boundary layer to the reacting surface was also given. The XRD results of $\mathrm{ZrC}$ films showed that at both $1200{ }^{\circ} \mathrm{C}$ and $1400{ }^{\circ} \mathrm{C}$ the (111) plane was the less preferred orientation, while (200) and (220) were the preferred planes. The degree of preferred orientation of $\mathrm{ZrC}$ films was found to decrease with increasing substrate-inlet gap. SEM results indicated that as the substrate-inlet gap increased from $70 \mathrm{~mm}$ to $170 \mathrm{~mm}$ for $1400{ }^{\circ} \mathrm{C}$, the films became more uniform with increased particle agglomeration. The cauliflower-like clusters of particles grew larger in size and covered the whole surface. By contrast, at $1200{ }^{\circ} \mathrm{C}$ the surface crystallites had complex facets that decreased in size as the substrate-inlet gap increased from $70 \mathrm{~mm}$ to $170 \mathrm{~mm}$

Keywords: Microstructure, Zirconium carbide films, Growth rate, Chemical vapour deposition, XRD

\section{Introduction}

Owing to its excellent physical properties, zirconium carbide $(\mathrm{ZrC})$ has been proposed as a possible new material to be used as a protective coating layer for TRISO (Tristructuralisotropic) nuclear fuel particle [1-3]. These properties include: high melting temperature

(about $3540{ }^{\circ} \mathrm{C}$ ), low density $\left(6.59 \mathrm{~g} / \mathrm{cm}^{3}\right)$ compared to other refractory carbides, chemical inertness to various reagents and high wear and corrosion resistance [1,3]. Many attempts have been made to grow $\mathrm{ZrC}$ films. 
Several techniques such as plasma spraying [4], sol gel synthesis [5,6], carbothermal reduction [7], magnetron sputtering [8], reactive melt infiltration [9] and chemical vapour deposition (CVD) [10-12], have been used to produce $\mathrm{ZrC}$. However, growing polycrystalline $\mathrm{ZrC}$ films with good stoichiometry has remained a challenge. When the deposition conditions are well managed, CVD produces $\mathrm{ZrC}$ films with relatively low levels of impurity and porosity [13]. This has made CVD the most suitable technique for growing multilayer coatings. The $\mathrm{ZrC}$ film parameters such as growth rate, surface morphology, stoichiometry, crystallite size, texture, structural defects and porosity are influenced by the CVD reactor geometry and deposition conditions [14]. This is because the reaction rates and mass transport of the inlet gases in the reaction chamber and on the substrate surface are governed by kinetics which depend on both reactor geometry and process parameters [15]. Chemical vapour deposition of materials carried out at atmospheric pressure operate in a mass transport-limited mode [14]. Therefore reactor and flow geometries are crucial for the film characteristics and growth rate [15]. Hence to produce $\mathrm{ZrC}$ films with good properties, deposition geometry and technique should be well managed.

During the course of our experimental work, it became evident that the position of the reactive gas inlet above the substrate had a distinct and unexpected effect on the growth parameters of $\mathrm{ZrC}$. This possibility has been mentioned before in a computational study by Vanka et al. [16]. They noted that the gap between the substrate and the inlet is a sensitive parameter since it determines the natural convection parameters and therefore affects growth dynamics of the coatings [16]. To our knowledge, no experimental work has been reported on the growth and properties of $\mathrm{ZrC}$ films in an induction heated CVD reactor at different substrate-gas inlet gaps. This study reports the influence of substrate-gas inlet gap on the growth rate, surface morphology and microstructure of $\mathrm{ZrC}$ films deposited on graphite substrates. The experimental work was performed in an atmospheric pressure induction 
heated graphite vertical wall CVD reactor using a $\mathrm{ZrCl}_{4} / \mathrm{CH}_{4} / \mathrm{H}_{2} / \mathrm{Ar}$ gas mixtures with the gas composition and flow rates held constant. Lui et al. [10] noted that the deposition process of $\mathrm{ZrC}$ films is controlled by gas nucleation at substrate temperature below $1250{ }^{\circ} \mathrm{C}$ and by surface reaction kinetics at substrate temperature above $1250{ }^{\circ} \mathrm{C}$. For this reason the temperature of substrate temperatures of $1200{ }^{\circ} \mathrm{C}$ and $1400{ }^{\circ} \mathrm{C}$ were selected for this work.

\section{Experimental}

\subsection{Apparatus}

$\mathrm{ZrC}$ films were deposited on graphite substrates using an inductively-heated vertical CVD system which was developed in-house at Necsa shown in Figure 1. The vertical graphite reaction chamber of $300 \mathrm{~mm}$ long with an internal diameter of $25 \mathrm{~mm}$ was used. The graphite substrate stage, with a diameter of $23 \mathrm{~mm}$, was fixed at the bottom of the reaction chamber. Two graphite substrates, each with a $10 \mathrm{~mm}$ diameter and $2.5 \mathrm{~mm}$ thick, were positioned on top of the substrate stage. The substrates were placed in such a way that the surface to be deposited on, was perpendicular to the gas feed line. A water-cooled tubular copper induction coil wound close to the exterior wall of the graphite reaction chamber was used as heat source.

The substrate-gas inlet gap (ZY) (see Figure 1) was varied from $70 \mathrm{~mm}$ to $90 \mathrm{~mm}, 120 \mathrm{~mm}$, $145 \mathrm{~mm}$ and $170 \mathrm{~mm}$. This was done by changing the inlet (Y) feed line lengths and maintaining the substrates at the same position on the top of the substrate stage $(\mathrm{Z})$. Changing the substrate position would result in changes to the temperature of the substrate and its immediate vicinity since the temperature at any point inside the reactor is dependent on its position relative to the induction heating coil. Prior to the start of deposition, the reaction chamber was flushed with argon by pressurising and depressurising five times. A rotary vane vacuum pump (not indicated in Figure 1) connected to the extraction line was used to pump 
away the argon and regulate the pressure in the reaction chamber during deposition. The process and instrumentation diagram is illustrated in [17].

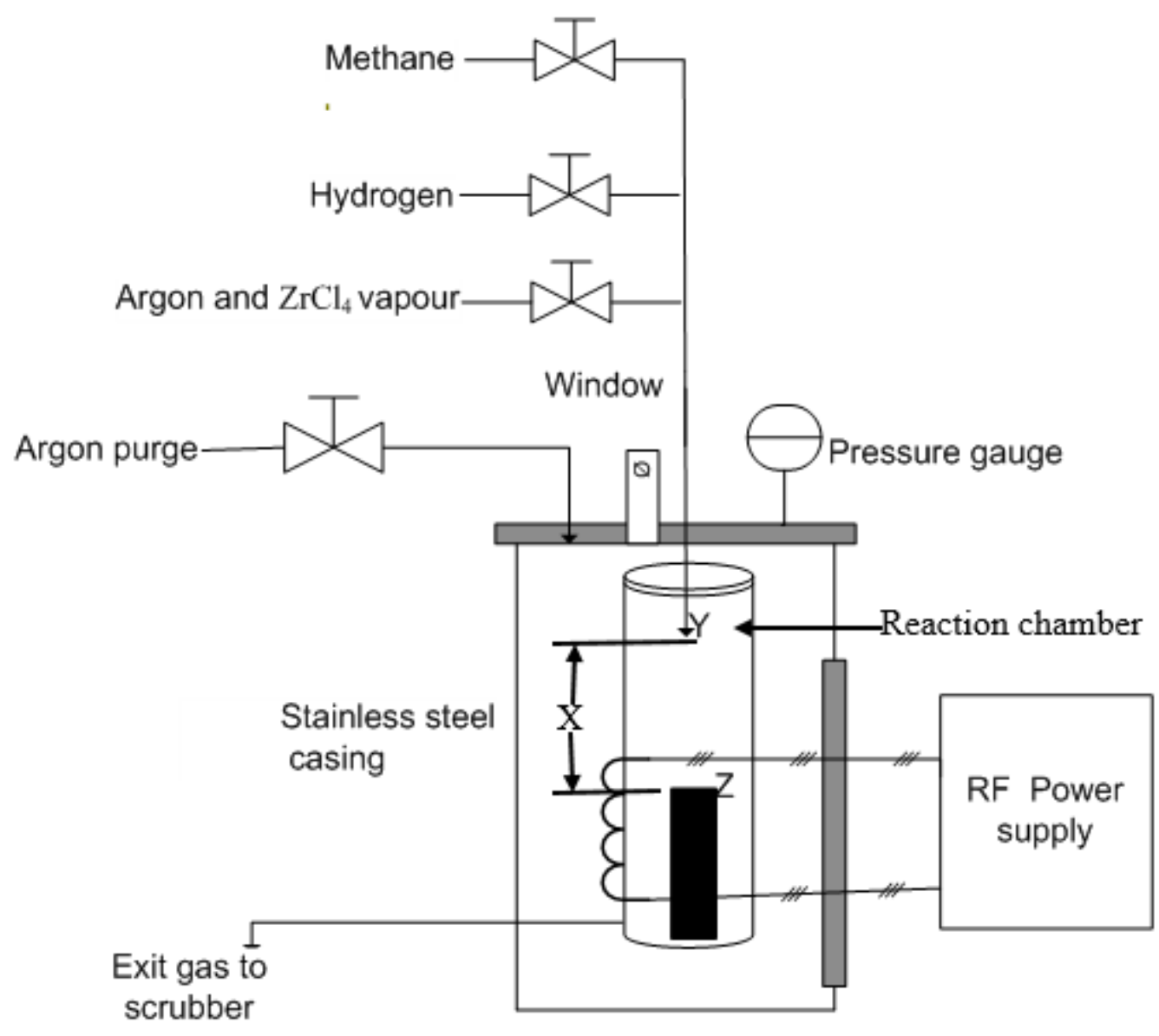

Figure 1. Schematic diagram of the CVD reactor system.

Anhydrous $\mathrm{ZrCl}_{4}$ powder (purity $>99.5 \%$, Hf $<50 \mathrm{mg} / \mathrm{kg}$ ) supplied by Sigma-Aldrich and methane (purity $>99.999 \%$ ) were respectively used as zirconium and carbon precursors for the deposition of $\mathrm{ZrC}$ films. Hydrogen gas was used to provide a reducing environment for $\mathrm{ZrCl}_{4}$ and to dilute the $\mathrm{HCl}$ effluent. The $\mathrm{ZrC}$ deposition process may be described by the overall chemical reaction given by Equation (1).

$$
\mathrm{ZrCl}_{4}(g)+\mathrm{CH}_{4}(g) \rightarrow \mathrm{ZrC}(s)+4 \mathrm{HCl}(g)
$$

The $\mathrm{ZrCl}_{4}$ powder was maintained at a temperature of $300{ }^{\circ} \mathrm{C}$ in order to control its vapour pressure. The $\mathrm{ZrCl}_{4}$ vapour was then swept into the reaction chamber by argon carrier gas. 
The $\mathrm{ZrCl}_{4}$ mass transfer rate to the rector was controlled by regulating the argon carrier flow rate. The flow rates of argon, hydrogen and methane were controlled by manual flow meters. The deposition was conducted at atmospheric pressure at two substrate temperatures viz. $1200{ }^{\circ} \mathrm{C}$ and $1400{ }^{\circ} \mathrm{C}$ for 2 hours. The deposition parameters are indicated in Table 1.

Table 1. Experimental growth parameters for $\mathrm{ZrC}$ films.

\begin{tabular}{ccccc}
\hline $\begin{array}{c}\text { Time } \\
(\mathbf{h})\end{array}$ & $\begin{array}{c}\text { Pressure } \\
(\mathbf{a t m})\end{array}$ & $\begin{array}{c}\text { Substrate temperature } \\
\left({ }^{\circ} \mathbf{C}\right)\end{array}$ & $\begin{array}{c}\text { Substrate-gas inlet gap } \\
(\mathbf{m m})\end{array}$ & $\begin{array}{c}\text { Vapouriser } \\
\text { temperature }\left({ }^{\circ} \mathbf{C}\right)\end{array}$ \\
\hline \hline & 1.0 & 1200 and 1400 & $70-170$ & 300 \\
\hline Gases & Flow rate $\mathbf{Q}_{\mathbf{i}}(\mathbf{s c c m})$ & $\begin{array}{c}\text { Velocity } \mathbf{V}_{\mathbf{i}} \\
(\mathbf{m} / \mathbf{s})\end{array}$ & $\begin{array}{c}\text { Density } \mathbf{\rho}_{\mathbf{i}}\left(\mathbf{k g} / \mathbf{m}^{\mathbf{3}}\right) \\
0.442\end{array}$ & $\begin{array}{c}0.6669 \text { at } 20{ }^{\circ} \mathrm{C} \\
\mathrm{CH}_{4}\end{array}$ \\
26 & 0.0135 & 0.0838 at $20{ }^{\circ} \mathrm{C}$ & 1.1 at $20^{\circ} \mathrm{C}$ \\
$\mathrm{H}_{2}$ & 853 & 0.291 & 0.8494 at $300{ }^{\circ} \mathrm{C}$ & 0.88 at $20{ }^{\circ} \mathrm{C}$ \\
$\mathrm{Ar}$ & 562 & & 3.67 at $300{ }^{\circ} \mathrm{C}$ \\
\hline \hline
\end{tabular}

\subsection{Characterisation of $\mathrm{ZrC}$ films}

The crystal structure, phase composition, and the preferred orientations of the films were determined by X-ray diffraction (XRD) using a Bruker D8 Advance diffractometer with $\mathrm{Cu}$ $\mathrm{K}_{\alpha}(\lambda=0.15418 \mathrm{~nm})$ radiation. Diffracted data was collected using a LynxEye position sensitive detector. The phase composition of the films from the XRD patterns was analysed by the Rietveld refinement method using the TOPAS V4.2 [18] software package. The surface morphology of as deposited $\mathrm{ZrC}$ films was analysed using ultrahigh resolution fieldemission scanning electron microscopy (FE-SEM, Zeiss Ultra Plus) with working voltage set at $1 \mathrm{kV}$. 


\section{Results and Discussions}

\subsection{Gas flow parameters in the reaction chamber}

It was assumed that the total reactant gas pressure was uniform throughout the reactor space for the entire deposition time and the reactants did not react chemically in vapour phase to form $\mathrm{ZrC}$. Some of the gas properties are indicated in Table 1.

The velocity $V$ of the mixture of gases entering the reaction chamber was calculated using Equation (2).

$$
V=\frac{\sum_{i} \rho_{i} V_{i}}{\sum_{i} \rho_{i}}
$$

where $\rho_{i}$ and $V_{i}$ are the density and velocity of the $i^{t h}$ component respectively with $V_{i}=Q_{i} /\left(60 \pi r^{2}\right)$ and $r(0.32 \mathrm{~cm})$ being the radius of the inlet steel pipes. The velocity $V$ of the gas mixture was found to be $0.183 \mathrm{~m} / \mathrm{s}$.

The values of density, velocity and viscosity of $\mathrm{ZrCl}_{4}$ vapour was not included in the calculations since $\mathrm{ZrCl}_{4}$ vapour constituted the smallest (and negligible) fraction of the total gas mixture. The density of the gas mixture was estimated from Equation (3) and was found to be $0.393 \mathrm{~kg} / \mathrm{m}^{3}$.

$$
\rho=\frac{\sum_{i} \rho_{i} Q_{i}}{\sum_{i} Q_{i}}
$$

The viscosity of the gas mixture was calculated from Equation (4).

$$
\eta=\frac{\sum_{i} y_{i} \eta_{i} \sqrt{M_{i}}}{\sum_{i} y_{i} \sqrt{M_{i}}}
$$

where $y_{i}, M_{i}$ and $\eta_{i}$ are the mole fraction, molar weight and viscosity respectively of the $i^{\text {th }}$ component at the desired temperature. The mole fraction of an individual gas was 
determined from their volumetric flow rates as $y_{i}=Q_{i} / \sum_{i} Q_{i}[13]$. The viscosity of the gas mixture was found to be $2.92 \times 10^{-5} \mathrm{~Pa} \cdot \mathrm{s}$.

The growth of $\mathrm{ZrC}$ films on the substrate is controlled by $\mathrm{ZrCl}_{4} / \mathrm{CH}_{4}$ diffusion to the surface of the substrate. Assuming the concentration of $\mathrm{ZrCl}_{4} / \mathrm{CH}_{4}$ in the vicinity of the substrate surface tends towards zero, then the concentration drop between the bulk and the surface is equal to the inlet concentration $N_{o}$. The concentration of individual reactants in the mixture was calculated from Equation (5).

$$
N_{o}=\frac{y_{i} \dot{m}_{i}}{M_{i} Q_{i}}
$$

where $\dot{m}_{i}$ is the reactant mass transfer rate and $w_{i}$ is the molar fraction. In this study, the $\mathrm{ZrCl}_{4}$ concentration in the mixture was found to be $8.12 \times 10^{-8} \mathrm{~mol} / \mathrm{cm}^{3}$. The molecular volume of the growing $\mathrm{ZrC}$ layer $v_{k}$ is $15.67 \mathrm{~cm}^{3} / \mathrm{mol}$.

From the experimental parameters and gas properties, the Reynold's number $(R e)$ at the inlet inside the reaction chamber was found to be 61.7 , indicating that the flow of the reactants in the reaction chamber was mainly laminar. The Reynold's number was determined from Equation (6).

$$
\operatorname{Re}=\frac{V \rho d}{\eta}
$$

where $d=2.5 \mathrm{~cm}$ is the diameter of the reaction chamber.

Due to natural convection and the friction between the reactant flow and the substrate surface (viscosity of the reactants), the velocity of the reactants in the vicinity of the substrate surface reaches a minimum. The difference in the gas flow velocities at the substrate surface and the bulk gives rise to a stagnant boundary layer. The boundary layer thickness $\delta$ is related to the Reynold's number by Equation (7) [19]. 


$$
\delta=\sqrt{X} \sqrt{\frac{d}{\operatorname{Re}}}
$$

The boundary layer thickness was estimated to be $5.3 \mathrm{~mm}, 6.0 \mathrm{~mm}, 7.0 \mathrm{~mm}, 7.8 \mathrm{~mm}$ and 8.3 mm for substrate inlet gap $X$ equal to $70 \mathrm{~mm}, 90 \mathrm{~mm}, 120 \mathrm{~mm}, 145 \mathrm{~mm}$ and $170 \mathrm{~mm}$ respectively.

\subsection{Growth rate}

The change in film thickness per unit deposition time (i.e. the growth rate, $k$ ) was determined from Equation (8).

$$
k=\frac{m}{t A \rho_{Z r C}}
$$

where $m$ is the mass of the film, $A$ is the surface area of the substrate, $\rho_{\operatorname{ZrC}}\left(6.59 \mathrm{~g} / \mathrm{cm}^{3}\right)$ is the theoretical density of $\mathrm{ZrC}$ and $t$ is the deposition time. The deposition time was considered as the duration which the precursors flowed into the reactor.

The effect of substrate-inlet gap and substrate temperature on the growth rate of $\mathrm{ZrC}$ films is shown by Figure 2. From these plots, it is quite clear that the growth rate decreases almost linearly with increase in substrate-inlet gap at both temperatures. The results also show an increased growth rate when the temperature is increased from $1200{ }^{\circ} \mathrm{C}$ to $1400{ }^{\circ} \mathrm{C}$. The effect of the gas inlet position may be due to increased diffusion rate of reactant species across the boundary layer [20] and the temperature effect may be due to increased surface reaction kinetics at higher temperatures [21]. The transport of the reactants in the reaction chamber is controlled by complex fluid dynamics $[19,22]$. The detailed examination of fluid dynamics in the vertical wall CVD is not presented in this work. We shall limit our discussion to diffusion of the reactants through the boundary layer. The boundary layer give rise to changes in the reactant flow velocity which results in a concentration gradient of reactant gases in the vicinity of the substrate surface $[19,23]$. The reactant gas concentration in the vicinity of the 
substrate surface is usually higher when the gas inlet is closer to the substrate. The higher gas concentration results in an increased mass transfer rate and this increases the arrival rates of reacting species to the substrate surface. The flux $J$ of the reactant through the boundary layer in the vicinity of the substrate surface inside the reaction chamber is given by Equation (9).

$$
J=\frac{-D N_{0}}{\delta}
$$

where $D$ is diffusion constant (a proportionality constant between the molar flux due to molecular diffusion and the gradient in concentration of the reactant species) and $N_{o}$ is the concentration difference over the boundary layer thickness $\delta$ [23]. Therefore increasing the boundary layer thickness reduces the diffusion flux of the reactants. The growth rate $k$, in terms of diffusion flux, boundary layer thickness and substrate-inlet gap is expressed by Equation (10).

$$
k=-v_{k} J=\left(v_{k} D N_{0} \sqrt{\frac{\operatorname{Re}}{d}}\right) \frac{1}{\sqrt{X}}
$$

where $v_{k}$ is the molecular volume of the crystal [27]. This expression shows that the growth rate is determined by the reciprocal of the square root of the substrate-inlet gap. This is in agreement with our experimental results obtained in Figure 2, where the growth rate is observed to have a linear relationship to the reciprocal of the square root of substrate-inlet gap.

It was also observed (by visual inspection) that when the substrate-inlet gap was wide (short inlet feed line), the amount of $\mathrm{ZrCl}_{4}$ gas diffusing out of the reaction chamber increased and deposited on the top lid of the stainless-steel casing. This might have decreased the concentration of $\mathrm{ZrCl}_{4}$ reaching the substrate and consequently contributed to decrease in $\mathrm{ZrC}$ film growth rate as substrate-inlet gap increased. 


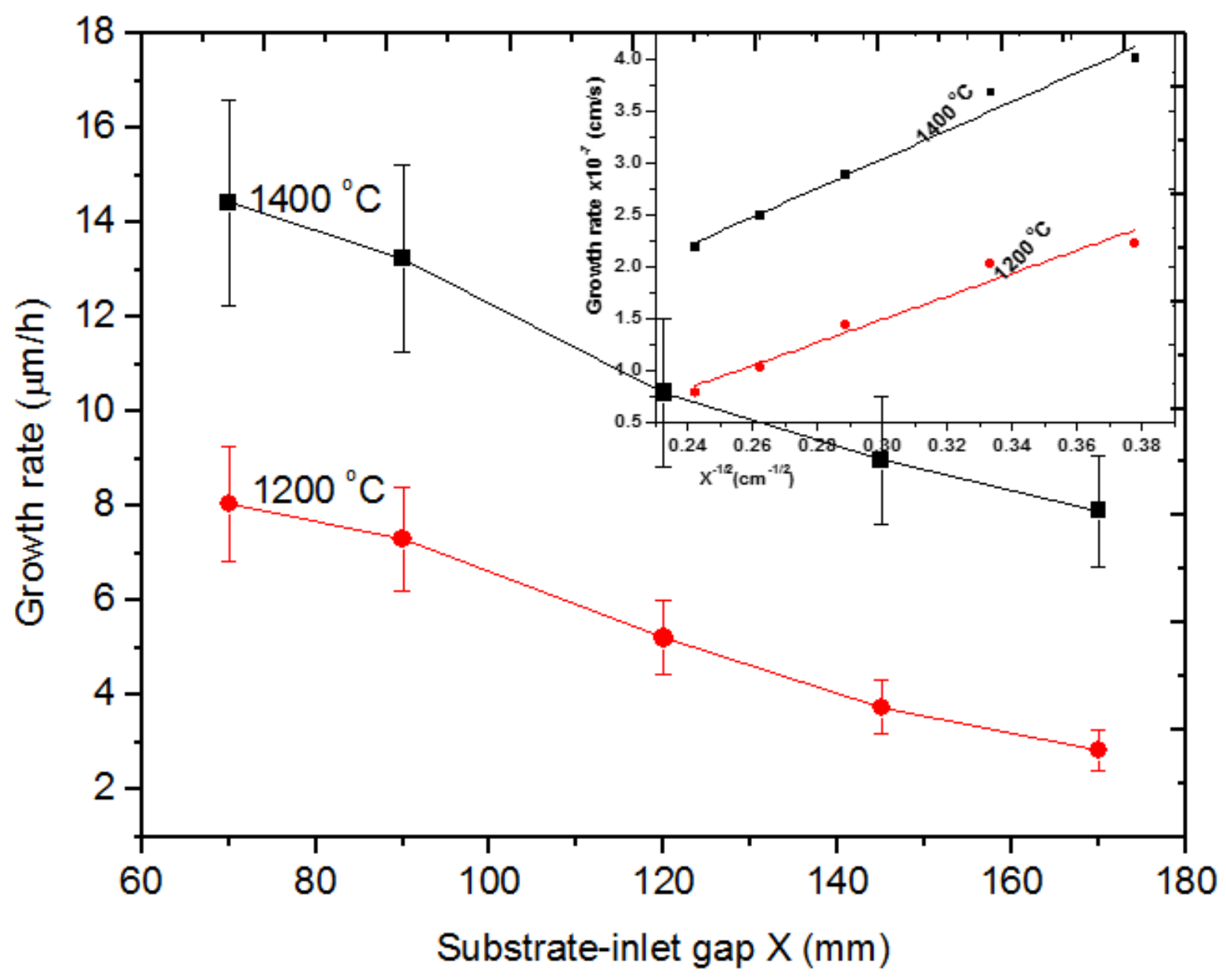

Figure 2. The plot showing the dependence of growth rate of ZrC films on substrate-inlet gap X. the insert shows the growth rate as a function of the reciprocal of the square root of $X$.

From the slope of the curves in the insert in Figure $2\left(1.111 \times 10^{-6} \mathrm{~cm}^{-3 / 2}\right.$ for $1200{ }^{\circ} \mathrm{C}$ and $1.393 \times 10^{-6} \mathrm{~cm}^{-3 / 2}$ for $1400{ }^{\circ} \mathrm{C}$ ) and the parameters of the multicomponent reactant gaseous mixture indicated in Section 3.1, the diffusion coefficients of the reactants for $\mathrm{ZrC}$ films growth process were determined from Equation (11).

$$
D=\left(\sqrt{\frac{d}{\operatorname{Re}}}\right) \frac{\text { slope }}{v_{k} N_{0}}
$$

The reactant diffusivity was found to be $0.176 \mathrm{~cm}^{2} / \mathrm{s}$ and $0.200 \mathrm{~cm}^{2} / \mathrm{s}$ for $1200{ }^{\circ} \mathrm{C}$ and $1400^{\circ} \mathrm{C}$ respectively. These values show that the derived diffusion coefficients increase marginally as the substrate temperature is increased. The values of diffusion coefficients above are likely to be low, since they are determined from the actual growth rate of the films, 
and yet not all the diffusing reactants are effectively used to form the $\mathrm{ZrC}$ film. The reactant loss may arise from parasitic reactions inside the reaction chamber and the reactants diffusing out of the chamber unreacted.

To explain the deposition mechanism, we use a concentration boundary layer model given in Figure 3. A number of steps are involved in the growth process; (1) The inlet gases $\left(\mathrm{ZrCl}_{4}\right.$ in Ar, $\mathrm{CH}_{4}$ and $\mathrm{H}_{2}$ ) are transported to the heated substrate surface or boundary layer, (2) gas phase reactions take place and the intermediate species (i.e. $\mathrm{CH}_{4}=\mathrm{C}+2 \mathrm{H}_{2}$ ) which form are transported (diffuse) through the boundary layer to the substrate, (3) the reactants and their intermediate species diffuse and are absorbed into the heated substrate surface. This produces the $\mathrm{ZrC}$ deposit and by-products, (4) the $\mathrm{ZrC}$ deposit then diffuse along the heated substrate surface forming crystallisation centres leading to the growth of the $\mathrm{ZrC}$ film according to the Burton-Cabrera-Frank step-flow mechanism [29]. In parallel with this, (5) the by-products and unreacted reactants are removed from the deposited film surface by convection, (6) some reactants and their intermediate product are lost within and from the reaction chamber, and (7) the by-products and unreacted reactants are transported away from the reaction chamber. The slowest process determines the actual film growth rate. For the deposition conditions and parameters used in this work, mass transport (diffusion) across the boundary layer becomes the rate controlling step. 


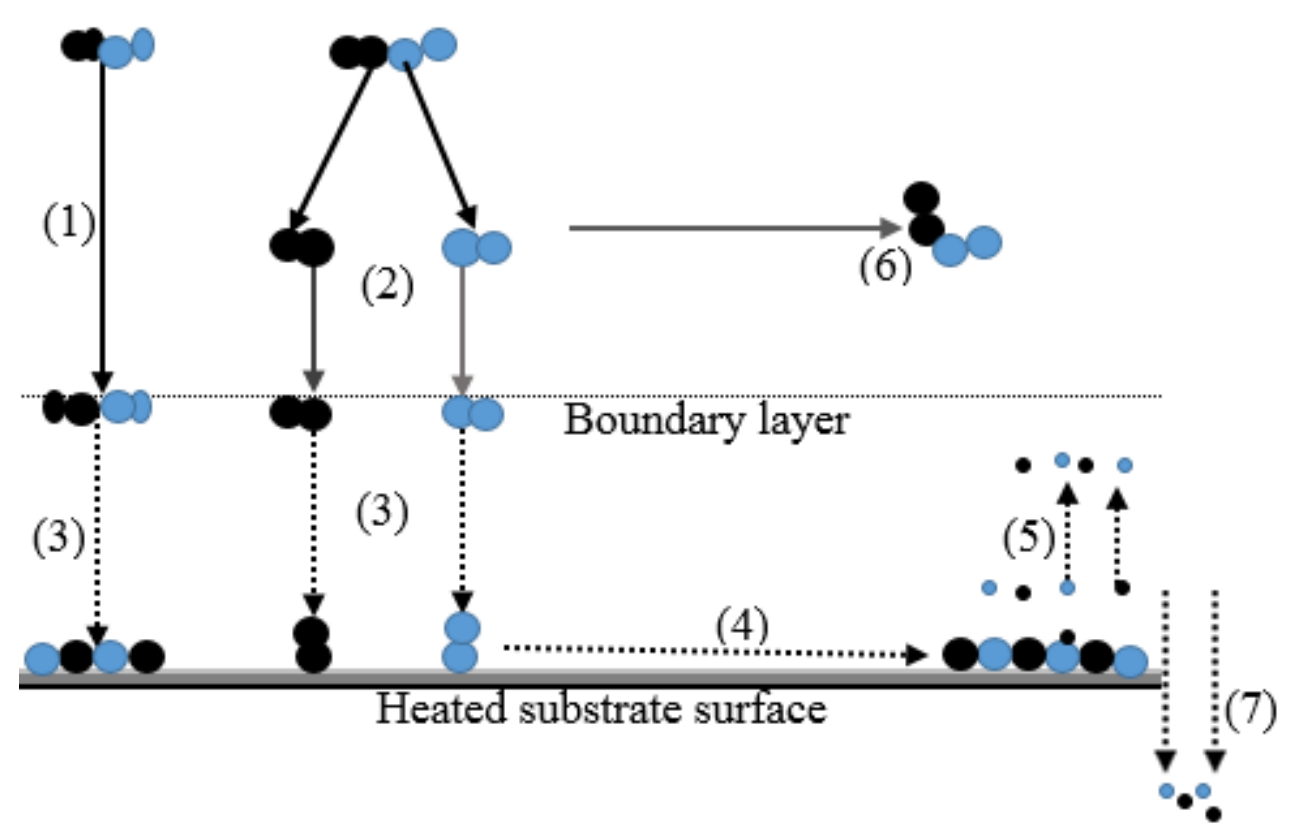

Figure 3. Concentration boundary layer model for CVD process of ZrC films in the vertical reaction chamber

\subsection{Crystallographic structure and phase composition}

The crystal structure and phase composition of all the deposited $\mathrm{ZrC}$ films were investigated by XRD analysis. Figure 4 and Figure 5 show the $\mathrm{XRD}$ patterns of $\mathrm{ZrC}$ films deposited at $1200{ }^{\circ} \mathrm{C}$ and $1400{ }^{\circ} \mathrm{C}$ respectively. The peaks and their corresponding Miller indices are also indicated in the figures. The diffraction peaks present were indexed within a cubic rock salt $(\mathrm{NaCl})$ structure and confirmed using the International Centre for Diffraction Data (ICDD) file number $\mathrm{ZrC}$ : 03-065-8833. Carbon peaks (matched with ICCD file number C: 00-0560159) are evident in XRD patterns as shown by Figure 4 and Figure 5. The carbon peak intensities were observed to increase with both substrate-inlet gap increase (from $70 \mathrm{~mm}$ to $170 \mathrm{~mm}$ ) and temperature increase (from $1200{ }^{\circ} \mathrm{C}$ to $1400{ }^{\circ} \mathrm{C}$ ). Phase quantification was performed by Rietveld refinement [30]. The results revealed that the samples consisted mainly of the $\mathrm{ZrC}$ phase and some amounts of free carbon. The $\mathrm{C} / \mathrm{ZrC}$ ratios at the two temperatures for each substrate-inlet gap was determined and plotted as shown in Figure 6. At $1200{ }^{\circ} \mathrm{C}$ the $\mathrm{C} / \mathrm{ZrC}$ ratio is lower than at $1400{ }^{\circ} \mathrm{C}$ for all the substrate-inlet gaps. The 
figure also shows a general increase of $\mathrm{C} / \mathrm{ZrC}$ ratio with increase in substrate-inlet gaps. The increase in free carbon may be attributed to the fact that the rate at which methane decomposes to form carbon and hydrogen increases with increasing temperature; higher growth rates imply higher fluxes of reactants to the deposition surface, and a higher probability for methane to decompose rather than to take part in a concerted reaction to form the carbide. Generally the diffusion rate of heavy gas molecules is lower compare to the light gas molecules and this corresponds to their participation in the growth process. When the substrate-inlet gap is narrowed, $\mathrm{ZrCl}_{4}$ is brought closer to the substrate and its participation in the growth process is improved, hence $\mathrm{C} / \mathrm{ZrC}$ decreases.

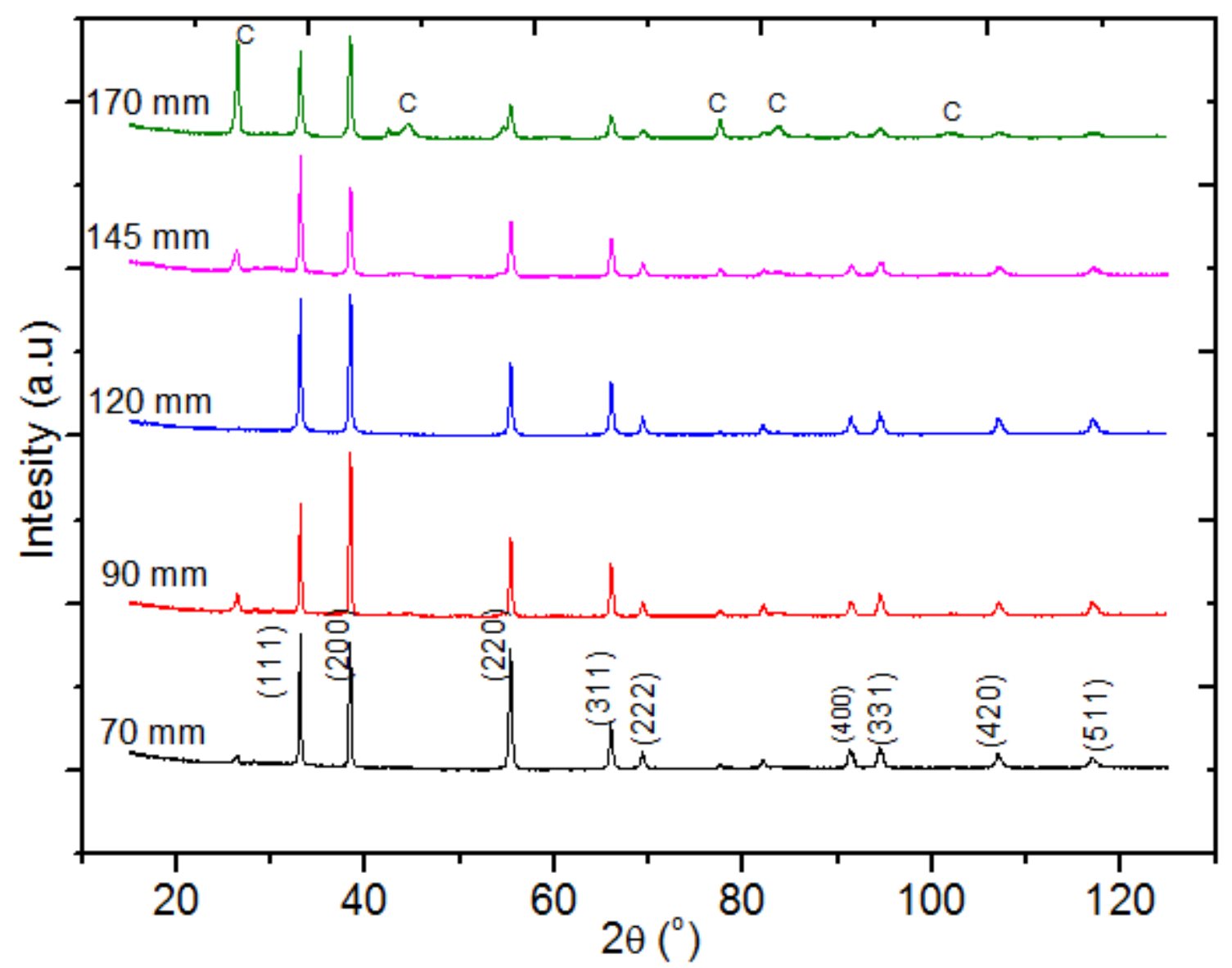

Figure 4. XRD patterns of $\mathrm{ZrC}$ films deposited at $1200{ }^{\circ} \mathrm{C}$ for different substrate-inlet gaps. 


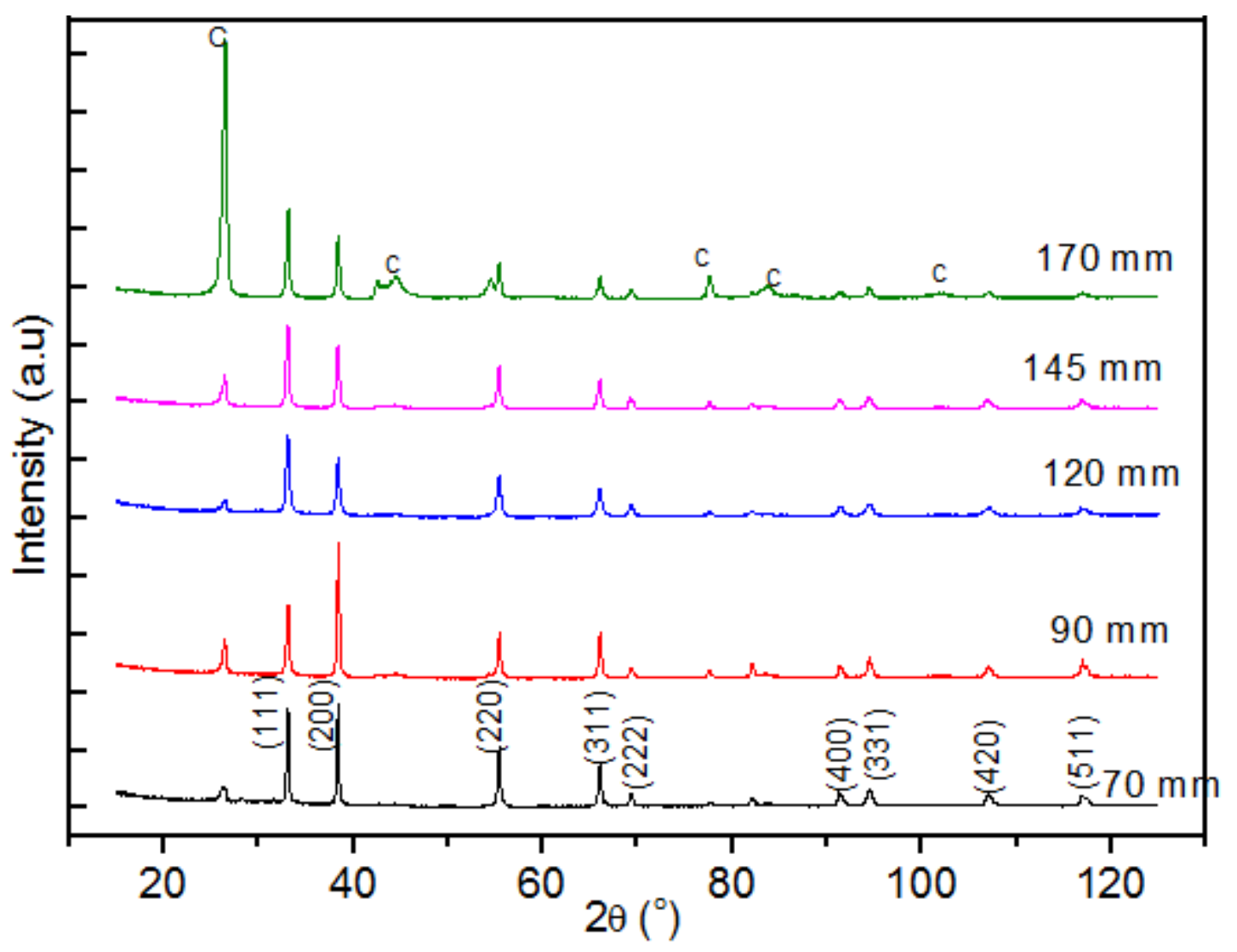

Figure 5. XRD patterns of $\mathrm{ZrC}$ films deposited at $1400^{\circ} \mathrm{C}$ for different substrate-inlet gaps.

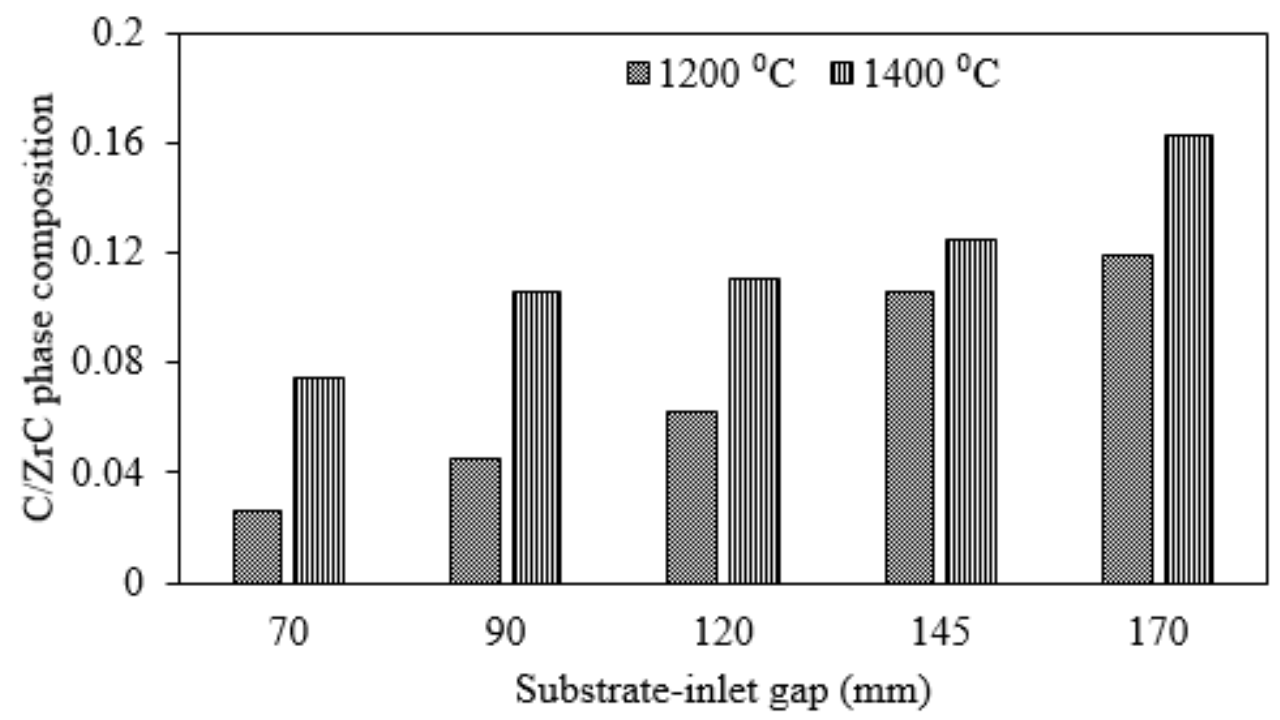

Figure 6. C/ZrC phase composition as a function of substrate-inlet gap. 


\subsection{Crystallite size}

The crystallite size of polycrystalline materials affects their mechanical properties [31]. Average crystallite size can be calculated from the Scherrer formula:

$$
D=\frac{0.94 \lambda}{B \cos \theta}
$$

where $\lambda$ is the $\mathrm{X}$-ray wavelength $(0.15418 \mathrm{~nm}), B$ is the full width at half maximum (FWHM) of a given diffraction peak, and $\theta$ is the Bragg angle [30] .

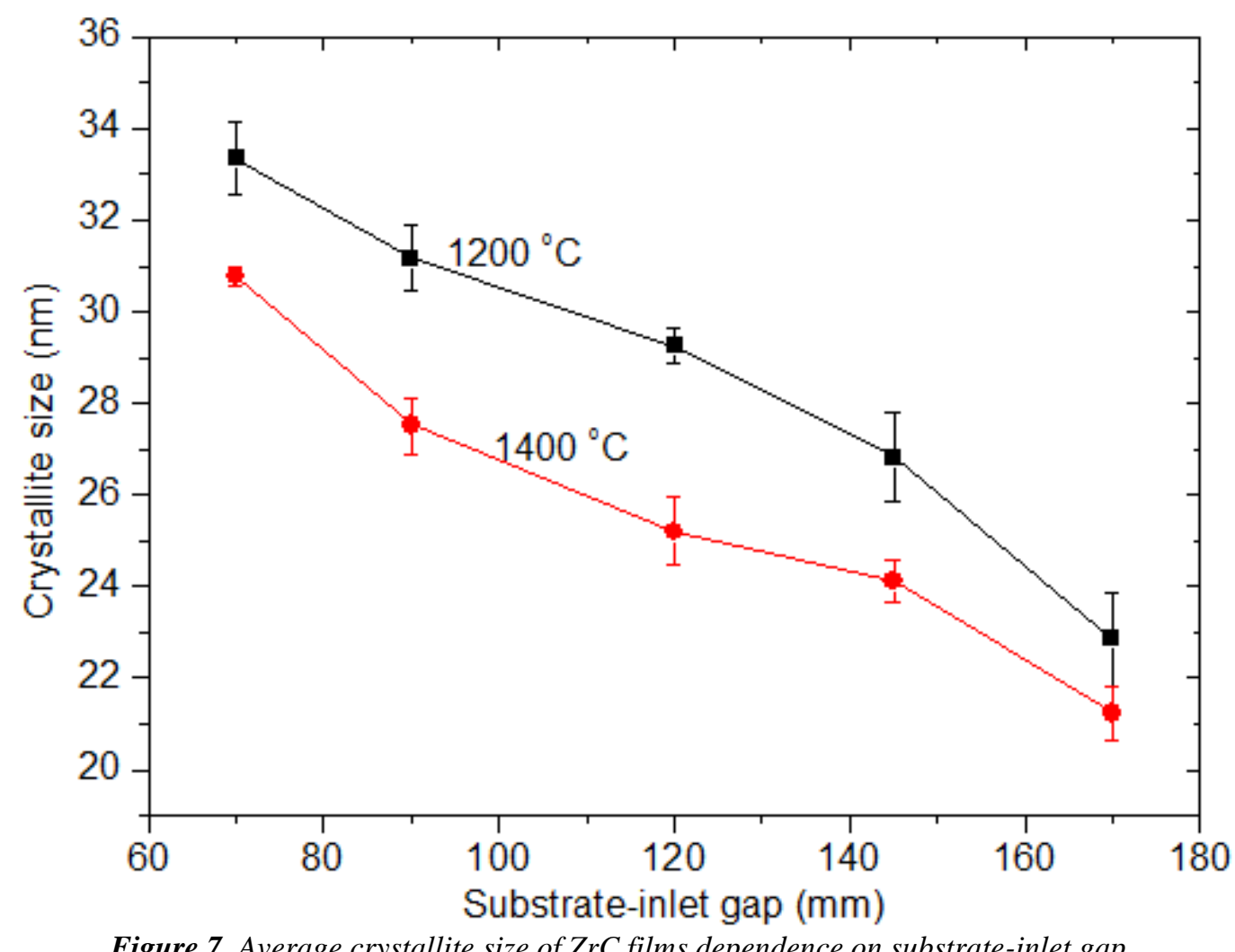

Figure 7 illustrates the dependence of average crystallite size of $\mathrm{ZrC}$ films on substrate-inlet gap at $1200{ }^{\circ} \mathrm{C}$ and $1400{ }^{\circ} \mathrm{C}$. The average crystallite size decreased from $33.3 \pm 0.8 \mathrm{~nm}$ to $22.8 \pm 1.0 \mathrm{~nm}$ for $\mathrm{ZrC}$ films deposited at $1200{ }^{\circ} \mathrm{C}$ and from $30.8 \pm 0.2 \mathrm{~nm}$ to $21.2 \pm 0.6 \mathrm{~nm}$ for films deposited at $1400{ }^{\circ} \mathrm{C}$ as the substrate-inlet gap increased from $70 \mathrm{~mm}-170 \mathrm{~mm}$. This reduction in average crystallite size might be due to two reasons. The reduced reactant concentrations at the substrate surface at wider substrate-inlet gaps may retard crystallite 
growth. Furthermore, as indicated in Figure 6, the increase in substrate-inlet gap results in an increase in the amount of free carbon. This free carbon, which is deposited as a secondary phase, acts as an impurity in the deposited film. The presence of carbon impurities in the $\mathrm{ZrC}$ films may also cause retardation in the crystallite growth.

\subsection{Peak broadening and lattice strain}

Figure 8 shows a plot of the FWHM for the (200) diffraction peak as a function of substrateinlet gap. From this figure, it is quite clear that the FWHM increases with substrate-inlet gap indicating peak broadening. Broadening of XRD peaks indicates a possible decrease in crystallite size (grain refinement) and/or the presence of lattice strain in the material [32].

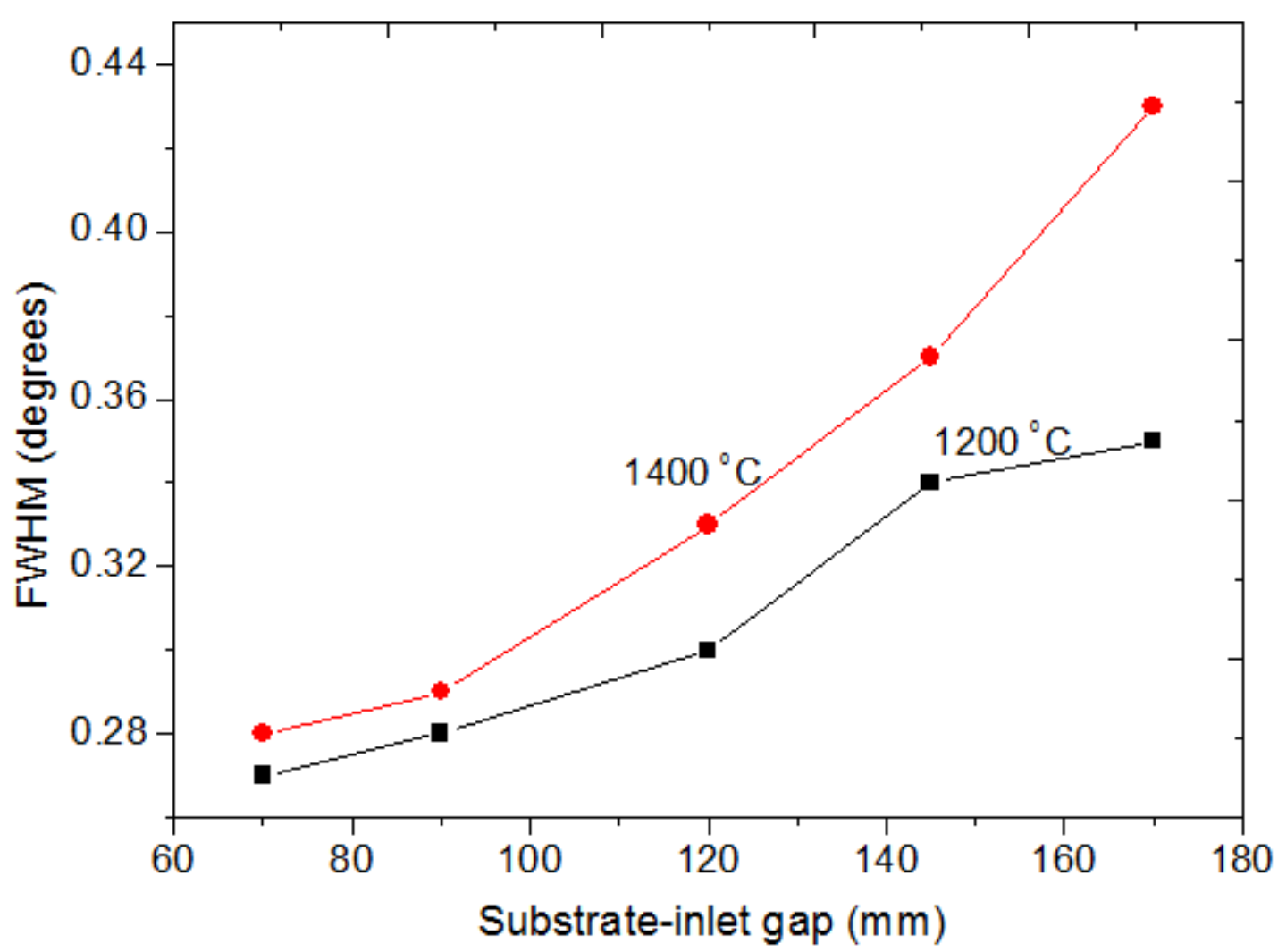

Figure 8. FWHM of a (200) peak as a function of substrate-inlet gap at $1200{ }^{\circ} \mathrm{C}$ and $1400{ }^{\circ} \mathrm{C}$.

Strain is a measure of distortions and crystal imperfections in the material. The strain is calculated from FWHM, denoted by $B$, and diffraction angle $\theta$ using Equation (13) [33]. 


$$
\varepsilon=\frac{B}{4 \tan \theta}
$$

The results in Figure 9 show that as the substrate-inlet gap increases, the strain in the $\mathrm{ZrC}$ films increased. The strain in the films is likely to have been introduced in the lattice planes during deposition by chemical and thermal processes. Polycrystalline films deposited on a substrate are usually in a strained state [34]. The increase in strain in the film as the substrateinlet gap increased may be due to reduced film thickness, decreased reactant concentrations, the effects of crystallite size, and also the increase in impurities (free carbon). Strain causes the interplanar spacing to change from stress free values to values comparable to the amount of stress introduced [31,35]. A very thin film is likely to be discontinuous [15], introducing stress in the material.

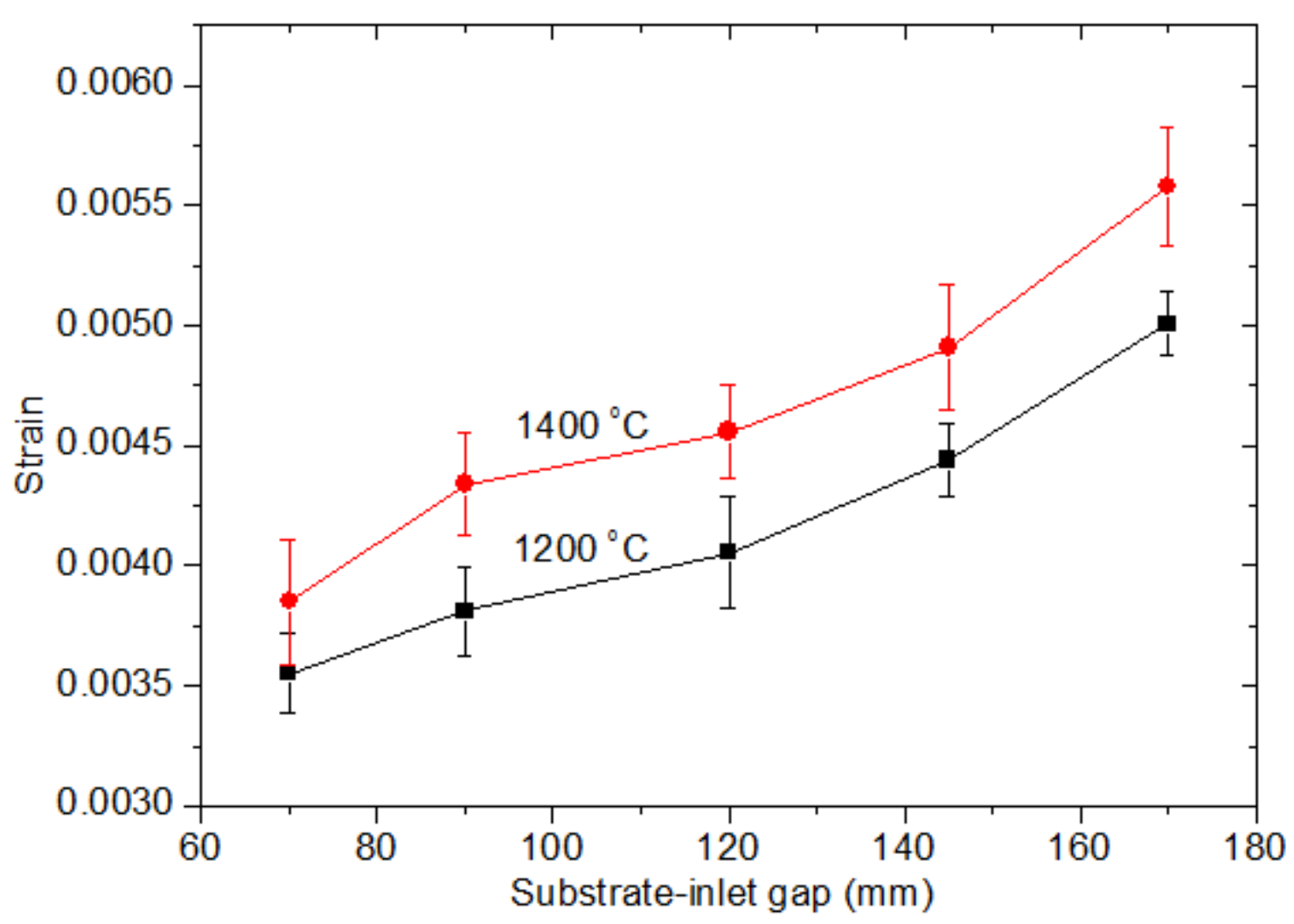

Figure 9. Effect of substrate-inlet gap on lattice strain at $1200{ }^{\circ} \mathrm{C}$ and $1400{ }^{\circ} \mathrm{C}$. 


\section{Preferred orientation}

To ascertain whether the crystals displayed preferred orientation, texture coefficients were determined. Texture coefficients $T(h k l)$ are calculated from Equation (14).

$$
T(h k l)=\frac{I(h k l) / I_{0}(h k l)}{(1 / N) \sum_{N} I(h k l) / I_{0}(h k l)}
$$

where $I(h k l)$ is the relative intensity of the (hkl) plane as measured from the diffraction pattern of the sample and $N$ is the number of diffraction peaks considered. In this case only the first five $\mathrm{ZrC}$ reflections of the $\mathrm{XRD}$ patterns of each sample were considered (i.e. $N=5$ ). The quantity $I_{0}(h k l)$ is the relative integrated intensity reference of the randomly oriented grains (powder of the sample) $[31,36]$. The value of $I_{0}(h k l)$ for the corresponding plane was obtained from the ICDD data file number ZrC: 03-065-8833.

Preferred orientation influences the properties of crystalline materials. Values of the texture coefficient, $T(h k l)$, less or equal to one means that the crystallites are randomly oriented, while a value of $T(h k l)$ greater than one implies preferred orientation of the crystallites in a given hkl direction [36-38]. Figure 10 and Figure 11 show the variation of texture coefficient with substrate-inlet gap at substrate temperature of $1200{ }^{\circ} \mathrm{C}$ and $1400{ }^{\circ} \mathrm{C}$ respectively.

At $1200{ }^{\circ} \mathrm{C}$, the texture coefficient is greater than one for all films, implying preferential orientation in all the indicated diffraction planes. The (220) plane is most preferred with a $T(h k l)$ value of 3.6 at $70 \mathrm{~mm}$. At $90 \mathrm{~mm}$ and $120 \mathrm{~mm}$, plane (200) was slightly more preferred than (220). There was a general decrease in the $T(h k l)$ values for all the diffraction planes at substrate inlet gaps of $145 \mathrm{~mm}$ to $170 \mathrm{~mm}$. The diffraction plane (111) was generally the least preferred orientation. This may be due high surface energy and reactant concentration when the substrate-inlet gap is narrowed. 


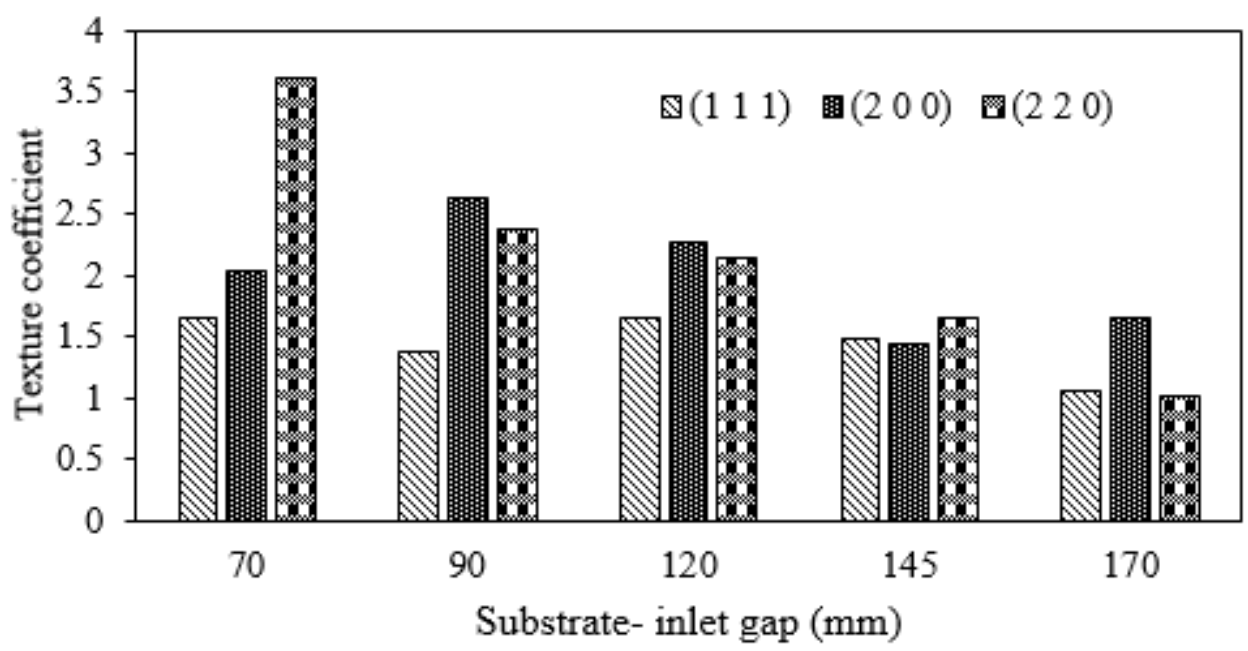

Figure 10. Texture coefficient of ZrC films deposited at $1200{ }^{\circ} \mathrm{C}$ as a function of substrate-inlet gap.

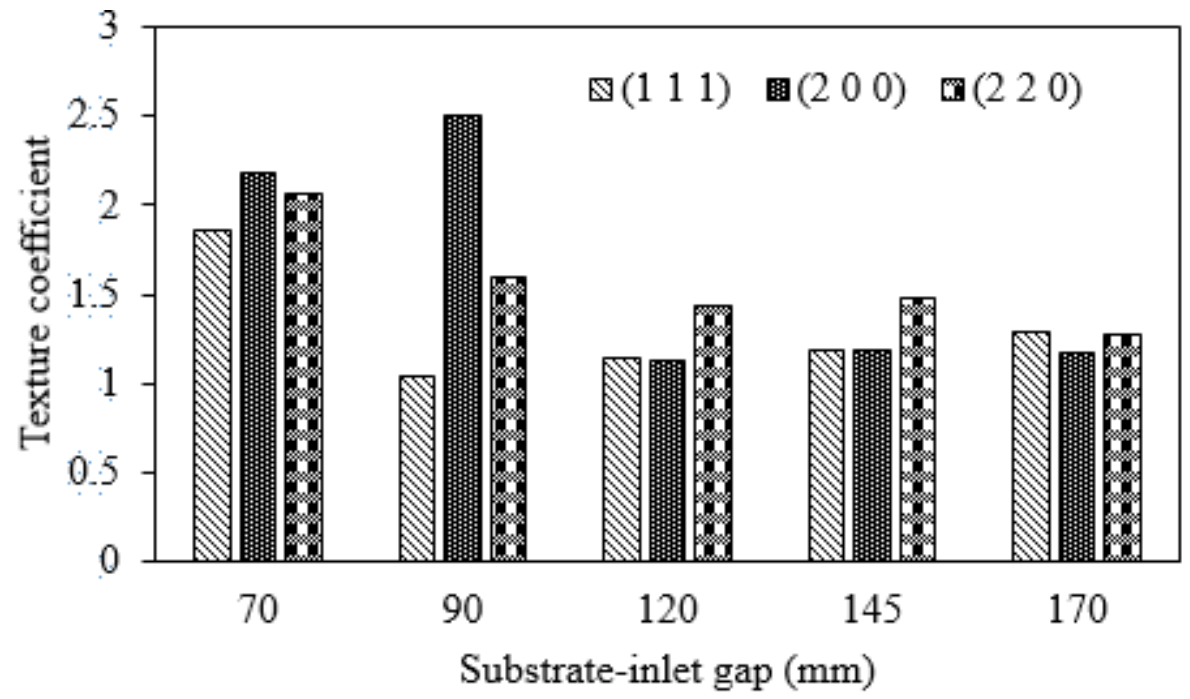

Figure 11. Texture coefficient of $\mathrm{ZrC}$ films deposited at $1400^{\circ} \mathrm{C}$ as a function of substrate-inlet gap.

For $\mathrm{ZrC}$ films deposited at $1400{ }^{\circ} \mathrm{C}$, the plane (200) was more preferred at $70 \mathrm{~mm}$ and 90 $\mathrm{mm}$. When the substrate-inlet gap widened, the preferred orientation shifted to (220). Similar to results at $1200{ }^{\circ} \mathrm{C},(111)$ was the less favoured diffraction plane. This may be due to increased temperature of $1400{ }^{\circ} \mathrm{C}$ which increases the surface energy and atomic mobility. However the accumulation of impurities such as free carbon on the substrate surface greatly influences the surface energy. 
The degree of preferred orientation $(\alpha)$ of each sample as a whole was determined by the standard deviation (from the powdered sample) of all the values of $T(h k l)$ for each sample calculated from Equation (15).

$$
\alpha=\sqrt{(1 / N) \sum_{N}\left[T(h k l)-T_{o}(h k l)\right]^{2}}
$$

The value of $T_{o}(h k l)$ is always equal to one since it represents the texture coefficient of the powder of the sample $[36,38,39]$. Figure 12 shows the variation of the degree of preferred orientation with substrate-inlet gap. All samples have $\alpha$-values greater than zero indicating good degree of preferential orientation at both temperatures. The $\alpha$-values decreases as the substrate-inlet gap and temperature increases. This indicates that to produce films with highly preferred orientation a relatively narrow substrate-inlet gap is recommended.

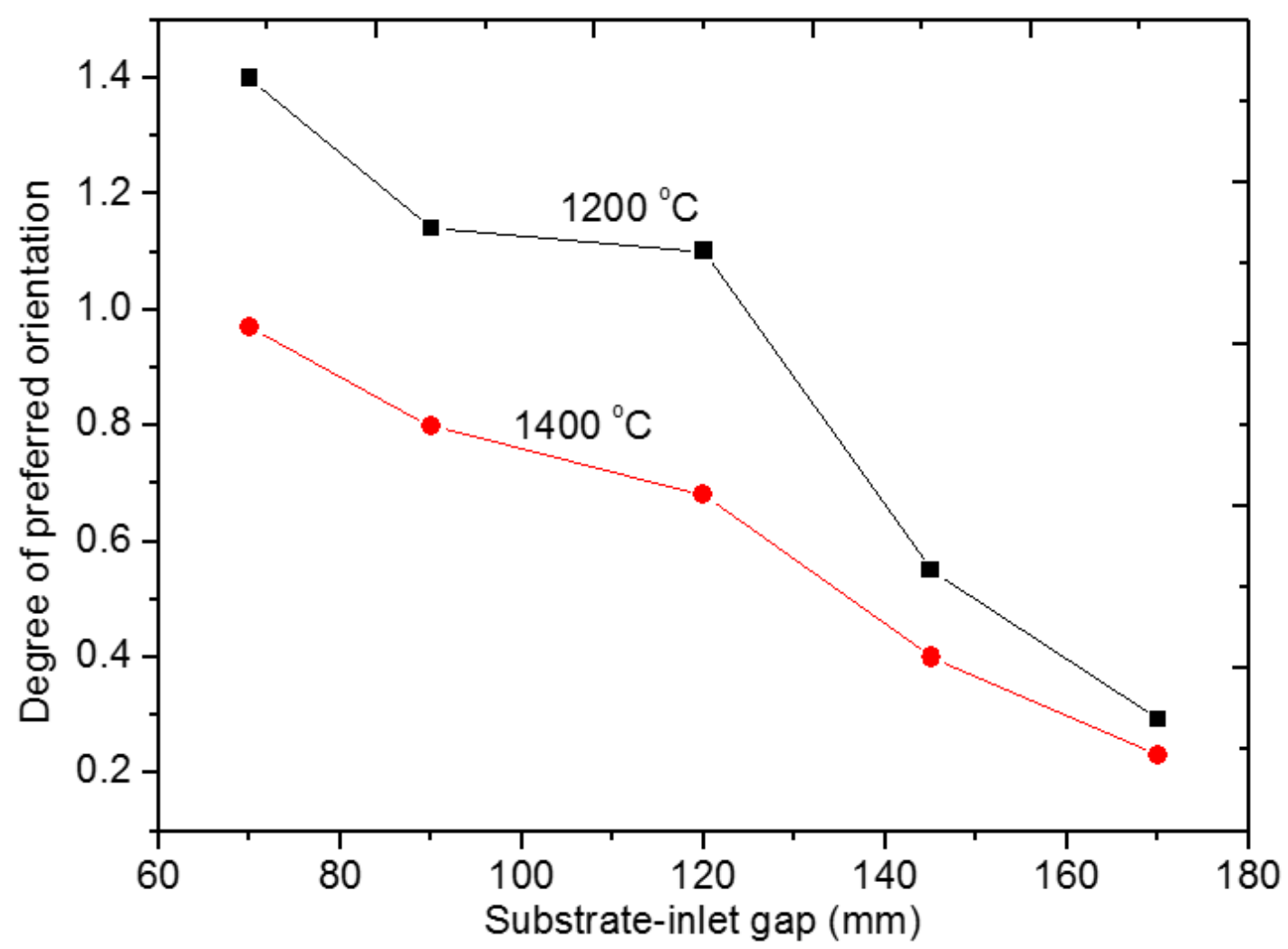

Figure 12. Effect of substrate-inlet gap on degree of preferred orientation of ZrC films. 

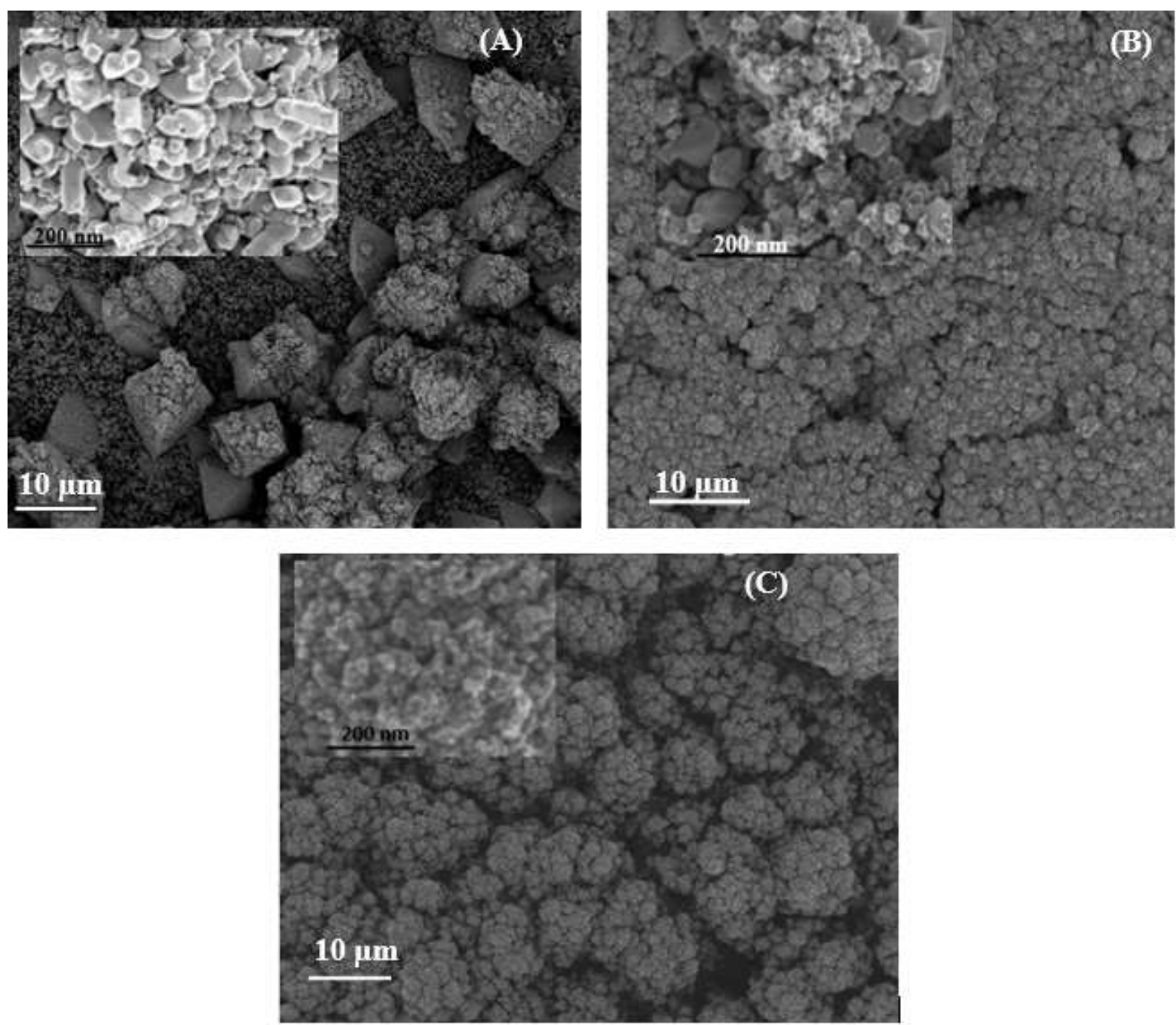

Figure 13. SEM images of ZrC films deposited at $120{ }^{\circ} \mathrm{C}$ for substrate-inlet gap of (A) $70 \mathrm{~mm}$, (B) $120 \mathrm{~mm}$ and (C) $170 \mathrm{~mm}$.

\subsection{Surface morphology and microstructure.}

The FE-SEM was used to examine the surface morphology and microstructure of $\mathrm{ZrC}$ films. The micrographs of $\mathrm{ZrC}$ film surfaces deposited at $1200{ }^{\circ} \mathrm{C}$ for different substrate-inlet gaps are depicted in Figure 13. At $70 \mathrm{~mm}$ (Figure 13 (A)), the $\mathrm{ZrC}$ film surface show a large complex facetted structure surrounded by small particles existing at the periphery and on top. These small particles have the same shape as the larger ones (see the high magnification insert in Figure 13 (A)). The surface morphology at substrate-inlet gap of $120 \mathrm{~mm}$ indicated in Figure 13 (B)) show small granules almost of the same size with very few openings on film surface. These small granules have the same structure (complex facets) as those at 70 
$\mathrm{mm}$ (see the insert Figure 13 (B)). At $170 \mathrm{~mm}$ (Figure 13 (C)), $\mathrm{ZrC}$ film surface show ballshaped particles clustered together forming a cauliflower-like shape. The cauliflower-like clusters of varying sizes are surrounded by numerous large openings, compared to that of the image at $120 \mathrm{~mm}$.
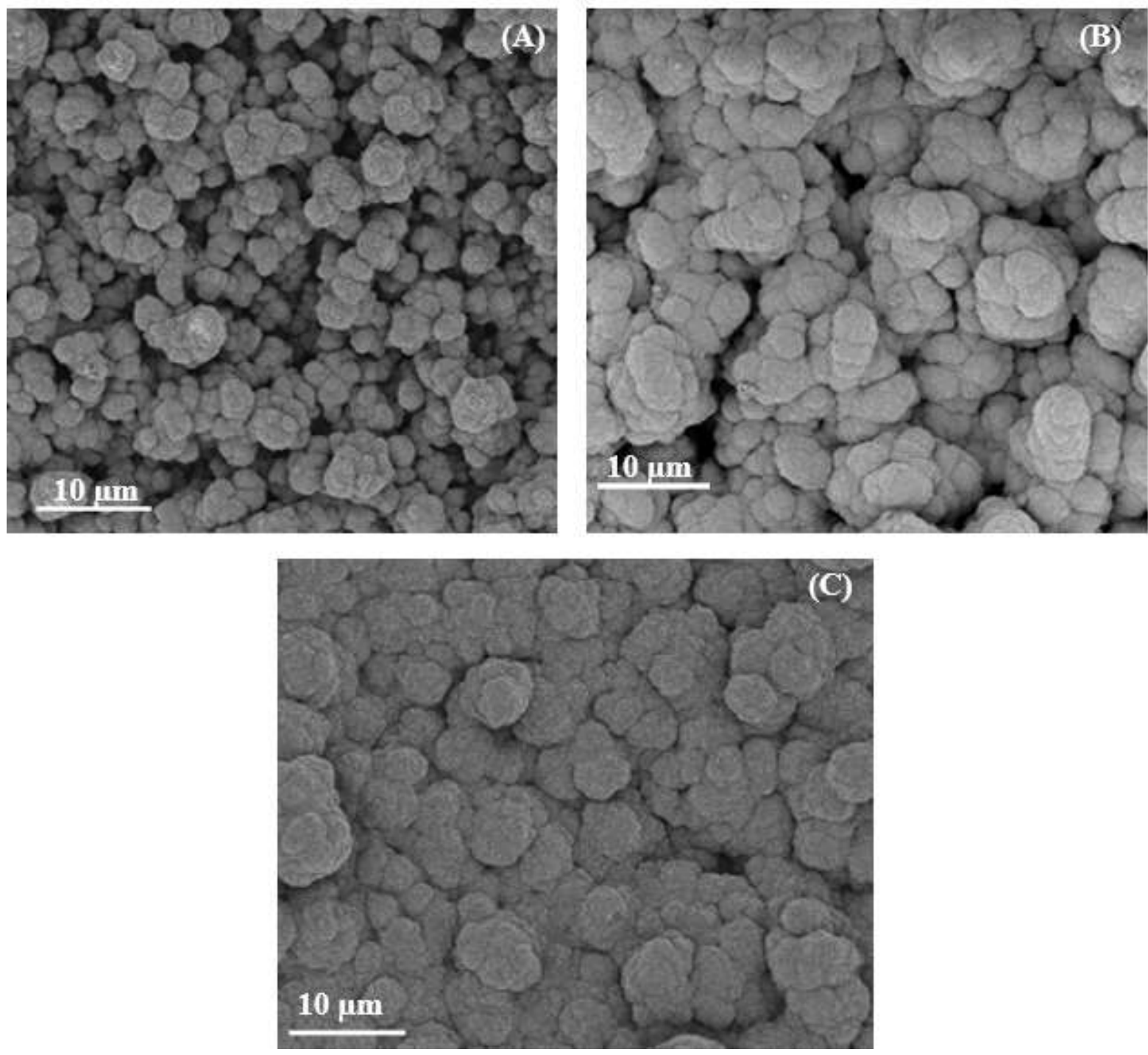

Figure 14. SEM images of $\mathrm{ZrC}$ films deposited at $1400^{\circ} \mathrm{C}$ for substrate-inlet gap of (A) $70 \mathrm{~mm}$, (B) $120 \mathrm{~mm}$ and (C) $170 \mathrm{~mm}$.

Figure 14 shows surface morphology of $\mathrm{ZrC}$ films deposited at $1400{ }^{\circ} \mathrm{C}$ for substrate-inlet gap of $70 \mathrm{~mm}$ (Figure 14 (A)), $120 \mathrm{~mm}$ (Figure 14 (B)) and $170 \mathrm{~mm}$ (Figure 14 (C)). At 70 $\mathrm{mm}$, the surface morphology consists of agglomerates of ball-like particles surrounded by openings. At $120 \mathrm{~mm}$ these agglomerates (cauliflower-like) become bigger and the size of the 
openings surrounding them reduces significantly. As the substrate-inlet gap increases to 170 $\mathrm{mm}$ the surface morphology is more uniform, dense and smoother with almost no openings around the clusters. The cauliflower-like clusters tend to pebble-like structure.

The average particle sizes (for the different gap conditions increased for the $1400{ }^{\circ} \mathrm{C}$ grown films. This can be attributed to the increase in the surface energy and mobility of the $\mathrm{ZrC}$ molecules on the surfaces of the deposited (poly-crystalline) $\mathrm{ZrC}$ crystals at the higher temperature. Another reason for the increase in particle size (agglomeration) as substrate-inlet gap increased may be due to the increase in carbon impurities in the films which acts as additional nucleation sites. Judging from these results, it is quite clear that the substrate-inlet gap and substrate temperature controls the morphology and growth uniformity of $\mathrm{ZrC}$ films.

\section{Conclusion}

$\mathrm{ZrC}$ films were prepared at atmospheric pressure on graphite substrates in a vertical CVD reactor. $\mathrm{ZrCl}_{4}-\mathrm{CH}_{4}-\mathrm{H}_{2}-\mathrm{Ar}$ mixtures were used at substrate temperature of $1200{ }^{\circ} \mathrm{C}$ and 1400 ${ }^{\circ} \mathrm{C}$ for 2 hours. For the deposition of the films in the reactor, the substrate-inlet gap was varied in the range of $70 \mathrm{~mm}-170 \mathrm{~mm}$. The results showed a higher growth rate for the $\mathrm{ZrC}$ films deposited at $1400{ }^{\circ} \mathrm{C}$ compared to $1200{ }^{\circ} \mathrm{C}$, and that the growth rate decreased with increasing substrate-inlet gap at both temperatures. The boundary layer thickness increased with increase in the substrate-inlet gap, resulting in lower fluxes and growth rates. The diffusion coefficient of the reactants was found to be $0.176 \mathrm{~cm}^{2} / \mathrm{s}$ and $0.200 \mathrm{~cm}^{2} / \mathrm{s}$ for growth temperature of $1200{ }^{\circ} \mathrm{C}$ and $1400{ }^{\circ} \mathrm{C}$ respectively. The diffusion of source materials through the boundary layer to the reacting surface was also illustrated using a model. The XRD results showed the formation of $\mathrm{ZrC}$ and some traces of free carbon. The $\mathrm{C} / \mathrm{ZrC}$ ratio increased with substrate-inlet gap at both temperatures, with $1400{ }^{\circ} \mathrm{C}$ having the highest ratio. There was a general decrease in average crystallite size with increasing substrate-inlet gap at 
both deposition temperatures. The lattice strain increased with substrate-inlet gap; this may be due to increase in lattice imperfection resulting from increased concentration of free carbon. The diffraction plane (111) was the less favoured orientation, whereas (200) and (220) were more favoured planes. The degree of preferred orientation decreased with substrate-inlet gap at the two temperatures. The samples deposited at $1200{ }^{\circ} \mathrm{C}$ had a higher degree of orientation than those deposited at $1400{ }^{\circ} \mathrm{C}$. For the $1200{ }^{\circ} \mathrm{C}$ substrate temperature, at a $70 \mathrm{~mm}$ substrate-inlet gap, the crystals had better developed facets with high crystallinity which deteriorated with increase in substrate-inlet gap. At $1400{ }^{\circ} \mathrm{C}$, as the substrate-inlet gap was increased from 70 to $170 \mathrm{~mm}$, the cauliflower-like structure became more uniform with increasing particle agglomeration.

\section{Acknowledgements}

The authors would like to acknowledge University of Pretoria, Busitema University and African Union for financial support. Necsa and the Department of Science and Technology of South Africa through the Nuclear Materials Development Network of the Advanced Metals Initiative is highly appreciated for the provision of laboratory space and experimental materials.

\section{References}

[1] H.O. Pierson, Handbook of Refractory Carbides \& Nitrides: Properties, Characteristics, Processing and Apps., William Andrew, 1996.

[2] M.K. Meyer, R. Fielding, J. Gan, Fuel development for gas-cooled fast reactors, J. Nucl. Mater. 371 (2007) 281-287.

[3] Y. Katoh, G. Vasudevamurthy, T. Nozawa, L.L. Snead, Properties of zirconium carbide for nuclear fuel applications, J. Nucl. Mater. 441 (2013) 718-742.

[4] D.J. Varacalle, L.B. Lundberg, H. Herman, G. Bancke, W.L. Riggs, Vacuum plasma sprayed zirconium carbide coatings, Surf. Coatings Technol. 68 (1994) 86-91.

[5] M. Dollé, D. Gosset, C. Bogicevic, F. Karolak, D. Simeone, G. Baldinozzi, Synthesis 
of nanosized zirconium carbide by a sol-gel route, J. Eur. Ceram. Soc. 27 (2007) 2061-2067.

[6] C. Ang, T. Williams, A. Seeber, H. Wang, Y.-B. Cheng, Synthesis and evolution of zirconium carbide via sol-gel route: features of nanoparticle oxide-carbon reactions, J. Am. Ceram. Soc. 96 (2013) 1099-1106.

[7] M.D. Sacks, C.-A. Wang, Z. Yang, A. Jain, Carbothermal reduction synthesis of nanocrystalline zirconium carbide and hafnium carbide powders using solution-derived precursors, J. Mater. Sci. 39 (2004) 6057-6066.

[8] C.-S. Chen, C.-P. Liu, C.-Y. Tsao, Influence of growth temperature on microstructure and mechanical properties of nanocrystalline zirconium carbide films, Thin Solid Films. 479 (2005) 130-136.

[9] X. Yang, Z. Su, Q. Huang, L. Chai, P. Zhong, L. Xue, A zirconium carbide coating on graphite prepared by reactive melt infiltration, J. Cent. South Univ. 21 (2014) 472476.

[10] Q. Liu, L. Zhang, L. Cheng, Y. Wang, Morphologies and growth mechanisms of zirconium carbide films by chemical vapor deposition, J. Coatings Technol. Res. 6 (2009) 269-273.

[11] K. Ikawa, Vapor deposition of zirconium carbide-carbon composites by the chloride process, J. Less Common Met. 29 (1972) 233-239.

[12] J. Gyu, S. Jung, J. Yeon, D. Jin, The effect of temperature on the growth and properties of chemical vapor deposited $\mathrm{ZrC}$ films on $\mathrm{SiC}$-coated graphite substrates, Ceram. Int. 41 (2015) 211-216.

[13] X.-T. Yan, Y. Xu, Chemical vapour deposition: an integrated engineering design for advanced materials, Springer Science \& Business Media, 2010.

[14] K.L. Choy, Chemical vapour deposition of coatings, Prog. Mater. Sci. 48 (2003) 57170 .

[15] S. Franssila, Introduction to microfabrication, John Wiley \& Sons, 2010.

[16] S.P. Vanka, G. Luo, N.G. Glumac, Parametric effects on thin film growth and uniformity in an atmospheric pressure impinging jet CVD reactor, J. Cryst. Growth. 267 (2004) 22-34.

[17] S. Biira, B.A.B. Alawad, H. Bissett, J.T. Nel, T.T. Hlatshwayo, P.L. Crouse, et al., Synthesis of $\mathrm{ZrC}$ coatings in an RF induction-heating CVD system, Thin Solid Films. (2016) Submitted.

[18] A.X.S. Bruker, TOPAS, Version 4.2, Bruker AXS, Karlsruhe, Ger. (2009).

[19] H.O. Pierson, Handbook of chemical vapor deposition: principles, technology and applications, William Andrew, 1999. 
[20] E.L. Cussler, Diffusion: mass transfer in fluid systems, Cambridge university press, 2009.

[21] P.M. Martin, Handbook of deposition technologies for films and coatings: science, applications and technology, William Andrew, 2009.

[22] C. Li, L. Huang, G.P. Snigdha, Y. Yu, L. Cao, Role of Boundary Layer Diff usion in Vapor Deposition Growth of Chalcogenide Nanosheets: The Case of GeS, ACS Nano. 6 (2012) 8868-8877.

[23] M.S. Kim, J.S. Chun, Effects of the experimental conditions of chemical vapour deposition on a TiC/TiN double-layer coating, Thin Solid Films. 107 (1983) 129-139.

[24] M. Henini, Handbook of Thin-Film Deposition Processes and Techniques, Second Edi, William Andrew, New York, 2000.

[25] D.I. Fotiadis, S. Kieda, K.F. Jensen, Transport phenomena in vertical reactors for metalorganic vapor phase epitaxy: I. Effects of heat transfer characteristics, reactor geometry, and operating conditions, J. Cryst. Growth. 102 (1990) 441-470.

[26] Y. Long, A. Javed, I. Shapiro, Z. Chen, X. Xiong, P. Xiao, The effect of substrate position on the microstructure and mechanical properties of $\mathrm{SiC}$ coatings on carbon/carbon composites, Surf. Coatings Technol. 206 (2011) 568-574.

[27] S.K. Ghandhi, R.J. Field, A re-examination of boundary layer theory for a horizontal CVD reactor, J. Cryst. Growth. 69 (1984) 619-622.

[28] R.C. Reid, J.M. Prausnitz, B.E. Poling, The properties of gases and liquids, 5 Edition, McGraw Hill Book Co., New York, NY, 1987.

[29] W.K. Burton, N. Cabrera, F.C. Frank, The growth of crystals and the equilibrium structure of their surfaces, Philos. Trans. R. Soc. London A Math. Phys. Eng. Sci. 243 (1951) 299-358. doi:10.1098/rsta.1948.0007.

[30] M. Ermrich, D. Opper, XRD for the analyst: Getting acquainted with the principles, PANalytical, 2013.

[31] B.D. Cullity, S.R. Stock, Elements of X-ray Diffraction, Pearson, 2001.

[32] K. Venkateswarlu, A.C. Bose, N. Rameshbabu, X-ray peak broadening studies of nanocrystalline hydroxyapatite by Williamson-Hall analysis, Phys. B Condens. Matter. 405 (2010) 4256-4261.

[33] V.D. Mote, Y. Purushotham, B.N. Dole, Williamson-Hall analysis in estimation of lattice strain in nanometer-sized $\mathrm{ZnO}$ particles, J. Theor. Appl. Phys. 6 (2012) 1-8.

[34] G. Janssen, Stress and strain in polycrystalline thin films, Thin Solid Films. 515 (2007) 6654-6664.

[35] R. Sharma, D.P. Bisen, U. Shukla, B.G. Sharma, X-ray diffraction: a powerful method 
of characterizing nanomaterials, Recent Res. Sci. Technol. 4 (2012) 77-79.

[36] J.P. Enríquez, X. Mathew, Influence of the thickness on structural, optical and electrical properties of chemical bath deposited CdS thin films, Sol. Energy Mater. Sol. Cells. 76 (2003) 313-322.

[37] S. Aksoy, Y.Y. Caglar, S. Ilican, M. Caglar, Effect of deposition temperature on the crystalline structure and surface morphology of $\mathrm{ZnO}$ films deposited on $\mathrm{p}-\mathrm{Si}, \mathrm{Adv}$. Control. Chem. Eng. Civ. Eng. Mech. Eng. (2010) 227-231.

[38] H.R. Moutinho, F.S. Hasoon, F. Abulfotuh, L.L. Kazmerski, Investigation of polycrystalline CdTe thin films deposited by physical vapor deposition, close-spaced sublimation, and sputtering, J. Vac. Sci. Technol. A. 13 (1995) 2877-2883.

[39] K.H. Kim, J.S. Chun, X-ray studies of $\mathrm{SnO} 2$ prepared by chemical vapour deposition, Thin Solid Films. 141 (1986) 287-295. 